\title{
The short-term effects of simultaneous treatment using two different methods of physiotherapy in the treatment of Adolescent Idiopathic Scoliosis: a pilot study B Wnuk, J Durmala*, J Dzierzega, J Piotrowski and M Walusiak
}

\author{
Address: Department of Rehabilitation University Hospital Medical Center of Silesia Ziolowa Str. 45/47 40-635 Katowice, Poland \\ Email: J Durmala* - jdurmala@sum.edu.pl \\ * Corresponding author
}

\author{
from 6th International Conference on Conservative Management of Spinal Deformities \\ Lyon, France. 21-23 May 2009 \\ Published: I4 December 2009 \\ Scoliosis 2009, 4(Suppl 2):O30 doi:I0.II86/I748-7|6I-4-S2-O30
}

This abstract is available from: http://www.scoliosisjournal.com/content/4/S2/O30

(c) 2009 Wnuk et al; licensee BioMed Central Ltd.

\section{Goal}

The assessment of the influence of joint physiotherapy (DoboMed and OTM Kaltenboru - Evjenth) on the function of the respiratory system and the morphology of the ribcage in short-term intensive physiotherapy within the Department of Rehabilitation.

\section{Materials and methods}

Thirty girls with AIS (mean age $=14.5 \mathrm{y}$; Cobb angle = range 12-40 degrees) were examined. The group was divided into two randomized subgroups. DoboMed alone was applied in group "D". DoboMed and manual therapy was applied in the group "DK".

The physiotherapy was continued for 3 weeks. Using spirometry, the strength of respiratory muscles (maximal inspiratory and expiratory pressures- MIP, MEP) was measured. Kyphosis (plurimeter-V) and the angle of trunk rotation (ATR) in thoracic spine (Bunnell scoliometer) were measured twice: once before and once after therapy.

\section{Results}

The values of MIP and MEP ( $\mathrm{p}<0.01$ ) were significantly increased in both groups (before and after therapy). The group "DK", compared to the group "D", showed significant improvement in forced expiratory volume in one second - FEV1 $(p<0.05)$, an increase in kyphosis $(p<0.01)$ and a decrease in ATR $(\mathrm{p}<0.05)$.

\section{Conclusion}

The use of joint physiotherapeutic methods in the treatment of AIS adds to the functional improvement of the respiratory system and the morphology of the ribcage in a short time. 